\title{
The sensitivity of the alternative maximal accumulated oxygen deficit method to discriminate training status
}

Alessandro M. Zagatto, Fabio Y. Nakamura, Fabio Milioni, Willian E. Miyagi, Rodrigo A. B. de Poli, Johnny Padulo, Nicola L. Bragazzi \& Marcelo Papoti

To cite this article: Alessandro M. Zagatto, Fabio Y. Nakamura, Fabio Milioni, Willian E. Miyagi, Rodrigo A. B. de Poli, Johnny Padulo, Nicola L. Bragazzi \& Marcelo Papoti (2017) The sensitivity of the alternative maximal accumulated oxygen deficit method to discriminate training status, Journal of Sports Sciences, 35:24, 2453-2460, DOI: 10.1080/02640414.2016.1273539

To link to this article: https://doi.org/10.1080/02640414.2016.1273539

Published online: 03 Jan 2017.

Submit your article to this journal ¿

Џلll Article views: 297

View Crossmark data ¿

Citing articles: 5 View citing articles $\longleftarrow$ 


\title{
The sensitivity of the alternative maximal accumulated oxygen deficit method to discriminate training status
}

\author{
Alessandro M. Zagatto (10) ${ }^{\mathrm{a}, \mathrm{b}}$, Fabio Y. Nakamurac, Fabio Milioni ${ }^{\mathrm{a}, \mathrm{b}}$, Willian E. Miyagi ${ }^{\mathrm{a}, \mathrm{b}}$, Rodrigo A. B. de Poli ${ }^{\mathrm{a}, \mathrm{b}}$, \\ Johnny Padulo $\mathbb{1}^{\mathrm{d}, \mathrm{e}}$, Nicola L. Bragazzi $\mathbb{1}^{\mathrm{f}}$ and Marcelo Papoti ${ }^{\mathrm{g}}$ \\ aLaboratory of Physiology and Sport Performance (LAFIDE), School of Sciences, São Paulo state University (Unesp), Bauru, Brazil; bPost-Graduate \\ Program in Movement Sciences, Sao Paulo State University (UNESP), Rio Claro, Brazil; 'Nucleus of High Performance in Sport, São Paulo, Brazil;

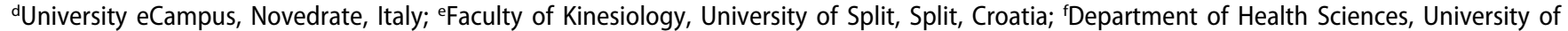 \\ Genoa, Genoa, Italy; ${ }^{9}$ School of Physical Education and Sport of Ribeirão Preto, Sao Paulo University, Ribeirão Preto, Brazil
}

\section{ABSTRACT}

The purpose of the study was to investigate the sensitivity of an alternative maximal accumulated oxygen deficit $\left(M_{A O D} D_{A L T}\right)$ method to discriminate the "anaerobic" capacity while comparing: least trained (LT) participants ( $n=12$ ), moderately trained (MT) participants $(n=12)$, endurance trained (ET) participants ( $n=16)$, and rugby (RG) players $(n=11)$. Participants underwent a graded exercise test

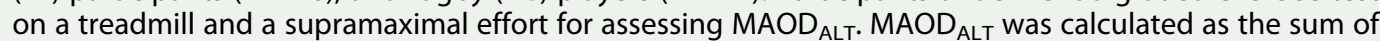
oxygen equivalents from the phosphagen and glycolytic metabolic pathways. MAOD ${ }_{A L T}$ was significantly higher $(P<0.05)$ in $\mathrm{RG}\left(64.4 \pm 12.1 \mathrm{~mL} \cdot \mathrm{kg}^{-1}\right)$ than in ET $\left(56.8 \pm 5.4 \mathrm{~mL} \cdot \mathrm{kg}^{-1}\right.$; effect size $[\mathrm{ES}]=0.77 ;+13.5 \%)$, MT $\left(53.8 \pm 5.3 \mathrm{~mL} \cdot \mathrm{kg}^{-1} ; \mathrm{ES}=1.08 ;+19.8 \%\right)$, and LT $\left(49.9 \pm 4.5 \mathrm{~mL} \cdot \mathrm{kg}^{-1} ; \mathrm{ES}=1.50\right.$;

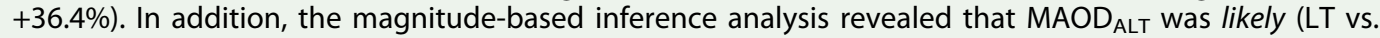
MT), very likely (MT vs. RG, and ET vs. RG) and most likely (LT vs. ET, and LT vs. RG) different between all groups, except for MT and ET, which presented an unclear difference. In conclusion, MAOD $\mathrm{ALT}$ was sensitive enough to distinguish the "anaerobic" capacity in individuals with different training status, especially for RG players compared with LT participants and MT participants.
ARTICLE HISTORY Accepted 9 December 2016

KEYWORDS

"Anaerobic" capacity; blood lactate response; excessive post-exercise oxygen consumption; physical conditioning

\section{Introduction}

The blood lactate response (i.e., post-exercise minus resting values) and fast phase of the excess post-exercise oxygen consumption (i.e., EPOC $C_{F A S T}$ ) have been jointly used to estimate the "anaerobic" capacity in a single exhaustive supramaximal effort, resulting in the so-called alternative maximal accumulated oxygen deficit $\left(M^{\prime} O_{A L T}\right)$ (Bertuzzi, Kiss, Damasceno, Oliveira, \& Lima-Silva, 2015; Bertuzzi et al., 2010; Brisola, Miyagi, da Silva, \& Zagatto, 2015; Zagatto, Bertuzzi, Miyagi, Padulo, \& Papoti, 2016; Zagatto \& Gobatto, 2012). This method seems to have good practical application due to its methodological simplicity compared to the conventional maximal accumulated oxygen deficit (MAOD), a time-consuming protocol requiring several exercise bouts to be performed (i.e., $\sim 10$ submaximal efforts and a supramaximal effort) (Noordhof, de Koning, \& Foster, 2010), while $M_{A A O D}$ ALT requires only two sessions (i.e., an incremental test and a supramaximal effort). Besides the assessment of "anaerobic" capacity (i.e., the maximal amount of energy that can be resynthesised by non-mitochondrial energy systems), $M A O D_{A L T}$ can also be used to estimate the energy contributions of the phosphagen $\left(\mathrm{E}_{\mathrm{PCr}}\right)$ and glycolytic $\left(\mathrm{E}_{[\mathrm{La}]}\right)$ metabolic pathways (Bertuzzi et al., 2015).
$M_{A O D}$ iLT is not statistically different from MAOD (Bertuzzi et al., 2010; Zagatto \& Gobatto, 2012; Zagatto, Bertuzzi, et al., 2016), and recently Zagatto, Bertuzzi, et al. (2016) reported that the best intensity to perform the supramaximal effort was $115 \%$ of the intensity associated with maximal oxygen uptake $\left(\mathrm{iVO}_{2 \max }\right)$, which leads to a greater MAOD $\mathrm{ALT}_{\text {outcome, as well }}$ as good reliability $(I C C=0.87)$. Furthermore, $M A O D_{A L T}$ was not altered after an acute high dose of taurine (Milioni et al., 2016) or caffeine (de Poli, Miyagi, Nakamura, \& Zagatto, 2016), demonstrating that MAOD ${ }_{A L T}$ is not affected by these ergogenic aids that improve performance. However, despite all the potential advantages of $M A O D_{A L T}$, it is still unclear if MAOD ${ }_{A L T}$ can distinguish the "anaerobic" capacity between groups with different training levels.

Gastin and Lawson (1994) noted higher MAOD values for sprint trained $\left(60 \mathrm{~mL} \cdot \mathrm{kg}^{-1}\right)$ than untrained $\left(50 \mathrm{~mL} \cdot \mathrm{kg}^{-1}\right)$ or endurance trained (ET) $\left(52 \mathrm{~mL} \cdot \mathrm{kg}^{-1}\right)$ individuals. In addition, Brisola et al. (2015) showed that acute sodium bicarbonate ingestion improved $M A O D_{A L T}$ and the $E_{[L a]}$, evidencing that $M A O D_{A L T}$ could be a sensitive enough measure to detect physiological adaptations in non-mitochondrial metabolism, resembling the specific training-related effects. Thus, the purpose of the present study was to investigate the sensitivity of $M A O D_{A L T}$ to distinguish the "anaerobic" capacity in groups

CONTACT Alessandro M. Zagatto azagatto@fc.unesp.br EDepartment of Physical Education, Sao Paulo State University (UNESP), Av. Eng. Luiz Edmundo Carrijo Coube, 14-01, Vargem Limpa, CEP 17033-360 Bauru, SP, Brazil

Laboratory where the research was conducted: Laboratory of Physiology and Sport Performance (LAFIDE), São Paulo state University (Unesp), School of Sciences, Bauru SP, Brazil;

๑) 2017 Informa UK Limited, trading as Taylor \& Francis Group 
with different levels of training. Given that the MAOD method is the most accepted test to assess the "anaerobic" capacity, we hypothesised that MAOD ${ }_{\text {ALT }}$ would be capable of distinguishing between distinct "anaerobic" performance levels. Therefore, in the current study the MAOD ${ }_{\mathrm{ALT}}$ values determined in least trained (LT) individuals, moderately trained (MT) individuals, ET runners, and rugby (RG) players who have a known high conditioning of "anaerobic" capacity, [i.e., MAOD $=\sim 99 \mathrm{~mL} \cdot \mathrm{kg}^{-1}$; (Moore \& Murphy, 2003)] were compared.

\section{Methods}

\section{Participants}

About 51 healthy men were recruited for this study and were allocated to the LT group ( $n=12)$, MT group $(n=12)$, recreational endurance runners $(n=16)$, and RG sevens group $(n=11)$. Those in LT engaged in $\leq 149 \mathrm{~min} \cdot \mathrm{wk}^{-1}$ of physical activity such as soccer, futsal, walking, and jogging; those in MT engaged in $\geq 150 \mathrm{~min} \cdot \mathrm{wk}^{-1}$ of physical activity around 3 times per week in activities such as soccer, futsal, jogging, and others, but were not athletes. The endurance runners systematically performed endurance training with a physical trainer and maintained a training volume of $\sim 200 \mathrm{~min} \cdot \mathrm{wk}^{-1}$ for $37.1 \pm 11.6 \mathrm{~km}$. Members of the national RG seven players trained at least 5 times per week, $845 \pm 122 \mathrm{~min} \cdot \mathrm{wk}^{-1}$ and regularly trained in RG for $11.8 \pm 6.3$ years. Participants characteristics are summarised in Table 1.

All participants were familiarised with the experimental procedures (i.e., maximal running on treadmill) and equipment (i.e., they performed exercise using the gas analyser at least twice to mimic the exercise procedure) and were instructed to eat the same light meal at least $2 \mathrm{~h}$ before the tests, to arrive euhydrated, and to perform no heavy training sessions in the $48 \mathrm{~h}$ before the test. The participants were instructed to avoid alcohol or caffeine ingestion during their participation in the study. All procedures were approved by the University's Institutional Review Board for Human Subjects (Human Research Ethics Committee - process number 645.784/2014) and were conducted according to the Declaration of Helsinki. Athletes were informed about the experimental procedures and risks, and provided written informed consent prior to the start of the study.

\section{Experimental procedures}

The experimental tests were conducted over a period of 10 days, with the participants performing 3 visits to the laboratory. On the first visit body composition was assessed using dual-energy X-ray absorptiometry (Hologic QDR,
Discovery, Bedford, USA); on the second visit a graded exercise test (GXT) was performed, followed by the supramaximal effort on the third visit. The exercise sessions were separated by a minimum interval of $48 \mathrm{~h}$.

The GXT and supramaximal effort tests were performed on a motorised treadmill (ATL, Inbramed, Inbrasport, Porto Alegre, RS, Brazil) with a fixed inclination of $1 \%$. To eliminate any influence of circadian variation, each participant completed all the trials at the same time period of a day in controlled environmental conditions (temperature of $20.3 \pm 1.5^{\circ} \mathrm{C}$ and relative humidity of $50.2 \pm 4.3 \%$ ). During the GXT and the supramaximal test, participants were verbally encouraged to perform maximally and wore a chest harness with the rope attached to the ceiling to ensure maximal effort without fall risk.

Prior to each testing effort, a warm-up lasting $5 \mathrm{~min}$ at $8 \mathrm{~km} \cdot \mathrm{h}^{-1}$ was performed and the tests started $5 \mathrm{~min}$ after the end of the warm-up.

\section{Physiological measurements}

The respiratory data were collected breath-by-breath during all tests using a Cosmed Quark CPET gas analyzer system (Quark CPET, Cosmed, Rome, Italy) coupled with a heart rate transmitter belt (Wireless HR 138 Monitor, Cosmed, Rome, Italy). Before the start of each test, the gas analyser was calibrated with a high-precision gas mixture and ambient air, whereas the volume transducer was calibrated before each test and verified after each test using a 3-L calibration syringe (Hans-Rudolph, Shawnee, Kans., USA), in accordance with the manufacturer's instructions. The breath-by-breath oxygen uptake $\left(\mathrm{V}_{2}\right)$ data were smoothed using a rolling 5 -s average and interpolated to provide $1-\mathrm{s}$ values for modelling $\dot{\mathrm{VO}}_{2}$ response (OriginPro 8.0; Origin Lab Corporation, Microcal, MA, USA).

To measure blood lactate concentration ([La]), blood samples were drawn from an earlobe $(25 \mu \mathrm{L})$ at rest before the GXT and supramaximal effort, and after the supramaximal effort. Blood samples were stored at $-20^{\circ} \mathrm{C}$ in tubes containing $50 \mu \mathrm{L}$ of sodium fluoride (1\%) and later analysed using an electrochemical lactate analyser (Yellow Springs Instruments model 2300, Ohio, USA) (measurement error of $\pm 2 \%$ ).

Graded exercise test (GXT) to assess maximal oxygen uptake $\left(\mathrm{VO}_{2 \max }\right)$ and the associated exercise intensity iV $\mathrm{O}_{2 \max }$

The GXT started at $8 \mathrm{~km} \cdot \mathrm{h}^{-1}$ (after warm-up) and the velocity increased by $1.5 \mathrm{~km} \cdot \mathrm{h}^{-1}$ every 2-min until voluntary exhaustion (Brisola et al., 2015; Zagatto, Bertuzzi, et al., 2016). The

Table 1. GXT variables for least trained (LT), moderately trained (MT), endurance trained runners (ET), and rugby players (RG).

\begin{tabular}{|c|c|c|c|c|c|c|}
\hline Variables & $\mathrm{LT}$ & MT & ET & RG & $F_{(3 ; 50)}$ & $P$-value \\
\hline Age (years) & $25 \pm 8(20-30)$ & $27 \pm 5(24-31)$ & $27 \pm 6(24-30)$ & $24 \pm 4(22-27)$ & 0.72 & 0.544 \\
\hline Height $(\mathrm{cm})$ & $173.4 \pm 4.4(170.6-176.2)$ & $175.4 \pm 7.2(170.8-180.0)$ & $177.0 \pm 6.3(173.6-180.3)$ & $179.9 \pm 8.6(174.1-185.7)$ & 1.91 & 0.141 \\
\hline Body mass $(\mathrm{kg})$ & $69.6 \pm 9.1(63.8-75.3)$ & $77.2 \pm 11.0(70.2-84.2)$ & $72.1 \pm 7.5(68.1-76.1)$ & $90.2 \pm 12.0(82.7-97.7)$ & 10.64 & 0.0001 \\
\hline Fat mass $(\%)$ & $16.1 \pm 3.3(14.0-18.3)$ & $18.1 \pm 4.8(15.1-21.2)$ & $13.9 \pm 5.7(10.9-16.9)$ & $14.5 \pm 4.8(11.3-17.7)^{\dagger \neq \&}$ & 2.02 & 0.124 \\
\hline
\end{tabular}

$P<0.05$ least trained group $(\mathrm{LT}){ }^{\ddagger}{ }^{\ddagger} P<0.05$ moderately trained group $(\mathrm{MA}) ;{ }^{\&} P<0.05$ endurance trained runner group (ET). Values are mean $\pm \mathrm{SD}(95 \% \mathrm{Cl})$ 
Borg scale (6-20) was used to assess the rating of perceived exertion (RPE) at the end of each stage and after exhaustion. $\dot{\mathrm{VO}}_{2}$ was measured during the entire test and the highest $\dot{\mathrm{VO}}_{2}$ average (i.e., $\mathrm{VO}_{2}$ average over the final $30 \mathrm{~s}$ of each stage) was assumed as $\dot{\mathrm{V}}_{2 \max }$, considering the verification of a plateau in $\dot{\mathrm{VO}}_{2}$ (variation in $\dot{\mathrm{VO}}_{2}<2.1 \mathrm{~mL} \cdot \mathrm{kg}^{-1} \cdot \mathrm{min}^{-1}$ between the final and penultimate stage of exercise). Secondary criteria were: (1) maximal HR (HRmax) $\geq 90 \%$ of predicted HRmax (Tanaka, Monahan, \& Seals, 2001); (2) respiratory exchange ratio $(\mathrm{RER}) \geq 1.10$, and (3) peak lactate $\geq$ $8.0 \mathrm{mmol} \cdot \mathrm{L}^{-1}$. The minimal exercise intensity at which the participant reached $\dot{\mathrm{VO}}_{2 \max }$ was considered as $\mathrm{iVO}_{2 \max }$ (Billat, Blondel, \& Berthoin, 1999). If the final stage had not been completed, the $\mathrm{iVO}_{2 \max }$ was determined using the method proposed by Kuipers, Verstappen, Keizer, Geurten, and van (1985) $\left[\mathrm{iV}_{2 \max }=\right.$ running speed of the final complete stage + (velocity increment after each stage $\times$ time sustained during the incomplete stage /total time of stage)].

The respiratory compensation point (RCP) was considered as the exercise intensity at which an increase in both ventilatory equivalents of $\mathrm{O}_{2}\left(\dot{\mathrm{VE}} / \dot{\mathrm{VO}}_{2}\right)$ and ventilatory equivalents of carbon dioxide production $\left(\mathrm{CO}_{2}\right)\left(\dot{\mathrm{V}} \mathrm{V} / \mathrm{V} \mathrm{CO}_{2}\right)$ over workload occurred (Zagatto, Miranda, \& Gobatto, 2011; Zagatto, Leite, Papoti, \& Beneke, 2016).

\section{Supramaximal exhaustive effort and assessment of $M A O D_{A L T}$}

Prior to the supramaximal exhaustive effort, $\dot{\mathrm{V}}_{2}$ was measured throughout $10 \mathrm{~min}$ of seated rest for $\mathrm{VO}_{2}$ baseline determination $\left(\dot{\mathrm{V}} \mathrm{O}_{2 \text { baseline; }}\right.$ considered as the $\dot{\mathrm{V}}_{2}$ average over the last $2 \mathrm{~min}$ of rest). The supramaximal effort was performed at $115 \%$ of $\mathrm{iVO}_{2 \max }$ as described by Zagatto, Bertuzzi, et al. (2016). Time-to-exhaustion of the supramaximal effort was recorded. Respiratory data were collected for another $7 \mathrm{~min}$ after the end of the supramaximal effort for determination of the fast component of excess

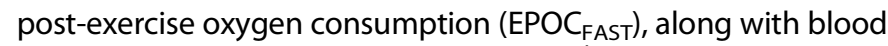
sampling from the earlobe in the $3 \mathrm{rd}, 5^{\text {th }}$, and 7 th minutes to determine [La]. The highest $\dot{\mathrm{V}}_{2}$ reached at exhaustion was also determined $\left(\mathrm{VO}_{2 \mathrm{EX}}\right)$, as the $\dot{\mathrm{VO}}_{2}$ average over the final $20 \mathrm{~s}$ of exercise.

$M A O D_{A L T}$ was calculated as the sum of the oxygen equivalents of the phosphagen metabolic pathway $\left(\mathrm{E}_{\mathrm{PCr}}\right)$ and glycolytic metabolic pathway $\left(\mathrm{E}_{[\mathrm{La}]}\right)$ (Bertuzzi et al., 2010; Brisola et al., 2015; de Poli et al., 2016; Zagatto \& Gobatto, 2012; Zagatto, Bertuzzi, et al., 2016) (test and retest ICC $=0.87$; data from our laboratory (Zagatto, Bertuzzi, et al., 2016)).

$E_{[L a]}$ was estimated by subtracting resting [La] from peak post-exercise blood lactate concentration $(\Delta[$ La] $)$, considering a value of $1 \mathrm{mmol} \cdot \mathrm{L}^{-1}$ to be equivalent to $3 \mathrm{~mL} \mathrm{O} \cdot \mathrm{kg}^{-1}$ body mass (di Prampero, 1981; di Prampero \& Ferretti, 1999). The $E_{\mathrm{PCr}}$ was considered to be the EPOC $\mathrm{FAST}$ (di Prampero \& Ferretti, 1999; Margaria, Edwards, \& Dill, 1933; Zagatto, Leite, et al., in press), which was estimated by multiplication of the amplitude and time constant of the fast component of a biexponential model (Equation (1)) using OriginPro 8.0 software (OriginLab Corporation, Microcal, Massachusetts, USA)
(Equation (2)) (di Prampero \& Ferretti, 1999; Margaria et al., 1933; Zagatto, Bertuzzi, et al., 2016).

$$
\begin{gathered}
\dot{\mathrm{V}} \mathrm{O}_{2(\mathrm{t})}=\dot{\mathrm{V}} \mathrm{O}_{2 \text { baseline }}+\mathrm{A}_{1}\left[\mathrm{e}^{-(\mathrm{t}-\delta) / \tau_{1}}\right]+\mathrm{A}_{2}\left[\mathrm{e}^{-(\mathrm{t}-\delta) / \tau_{2}}\right] \\
\mathrm{E}_{\mathrm{PCr}}=\mathrm{A} 1 \times \tau 1,
\end{gathered}
$$

where $\dot{\mathrm{VO}}_{2(\mathrm{t})}$ is the oxygen uptake at time $t, \dot{\mathrm{VO}}_{2 \text { baseline is the }}$ oxygen uptake at baseline, $\mathrm{A}$ is the amplitude, $\delta$ is the time delay, and $\tau$ is the time constant. 1 and 2 represent the fast and slow components, respectively.

\section{Statistical analysis}

The data are presented as mean \pm standard deviation (SD) and confidence interval of 95\% (Cl 95\%). Data normality was initially verified by the Shapiro-Wilk test, allowing the use of parametric statistical analysis. For analysis of the values from the supramaximal effort outcomes and $M_{A O D}{ }_{A L T}$ among groups, a one-way repeated measures analysis of variance was used for comparisons. In addition, Mauchly's sphericity test was applied to the data and sphericity was assumed to be violated when the " $F$ " test was significant. In case of sphericity violation, the Greenhouse-Geisser Epsilon correction was used. Analyses were completed using the "Bonferroni" post hoc test. In all cases, a significance level of $5 \%$ was assumed.

As the MAOD difference between trained participants was expected to be small (Heugas, Brisswalter, \& Vallier, 1997), magnitude-based inference analysis was also used. The raw outcomes were log-transformed prior to the analysis to reduce non-uniformity of error (Hopkins, Marshall, Batterham, \& Hanin, 2009). Magnitude-based inference was used to determine the practical significance and smallest worthwhile changes (non-clinical inference), using the method described by Batterham and Hopkins (2006). The threshold values for Cohen's d statistical power were considered as $>0.2$ (small), $>0.5$ (moderate), and $>0.8$ (large) (Cohen, 1988). A Cohen's unit of 0.2 was used to determine the smallest worthwhile value of change, and changes $\geq 75 \%$ likely to exceed the smallest important ES were considered meaningful. Using a Microsoft Excel $^{\oplus}$ spreadsheet designed for sports science research (Batterham \& Cox, 2006), mean effects, and the 95\% confidence limits were estimated to establish the percentage likelihood of each experimental condition having a positive/ trivial/negative effect on MAOD ${ }_{\text {ALT. }}$. Thus, the chances of benefit were qualitatively evaluated as follows: $0.5-5 \%=$ very unlikely; $5-25 \%$ = unlikely; $25-75 \%$ = possibly; $75-95 \%$ = likely; $95-$ $99.5 \%=$ very likely; and $>99.5 \%=$ most likely (Hopkins et al., 2009). When the positive and negative values were both $>5 \%$, the inference was classified as unclear.

\section{Results}

The age, height, and percentage of fat mass were similar among the groups, but the body weight in the RG was higher $\left(F_{(3.50)}=10.64 ; P=0.0001\right)$ compared with LT, MT, and ET (Table 1).

The physiological responses during the GXT are shown in Table 2. The $\dot{\mathrm{V}} \mathrm{O}_{2 \max }, \mathrm{iVO}_{2 \max }$, and RCP were statistically different between the groups $(P<0.001)$. The respiratory exchange 
Table 2. GXT variables for least trained (LT), moderately trained (MT), endurance trained runners (ET), and rugby players (RG).

\begin{tabular}{lccccc}
\hline & & & & \\
Variables & LT & MT & ET & Statistical \\
power (\%)
\end{tabular}

${ }^{\dagger} P<0.05$ least trained group (LT); ${ }^{\ddagger} P<0.05$ moderately trained group (MA); and $P<0.05$ endurance trained runner group (ET). Values are mean \pm SD (95\%Cl)

$\dot{\mathrm{V}}_{2 \max }$ : maximal oxygen uptake; $\mathrm{i}_{2} \mathrm{O}_{2 \mathrm{max}}$ : intensity associated with maximal oxygen uptake; $\mathrm{RCP}$ : respiratory compensation point;

ratio $(\mathrm{LT}=1.16 \pm 0.08, \mathrm{MT}=1.16 \pm 0.05, \mathrm{ET}=1.17 \pm 0.05$, and $\mathrm{RG}=1.18 \pm 0.05, P=0.843), \operatorname{RPE}(17.1 \pm 1.8,18.2 \pm 1.8$, $19.2 \pm 1.0$, and $18.8 \pm 1.3$, respectively; $P=0.115)$ and peak [La] $\quad(10.2 \pm 2.0,10.4 \pm 1.8,11.0 \pm 2.1$, and $12.0 \pm 4.0 \mathrm{mmol} \cdot \mathrm{L}^{-1}$, respectively; $P=0.353$ ) did not differ.

Table 3 shows the supramaximal effort values of time-toexhaustion, $\dot{\mathrm{V}} \mathrm{O}_{2}$ reached at exhaustion point $\left(\dot{\mathrm{VO}}_{2 \mathrm{EX}}\right)$, resting

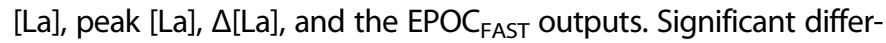
ences were observed only for time-to-exhaustion $(P=0.015)$ and $\dot{\mathrm{V}}_{2 \mathrm{EX}}(P=0.013)$, with the ET group presenting lower time-toexhaustion compared to the other groups. However, ET presented the highest $\dot{\mathrm{V}} \mathrm{O}_{2 \mathrm{EX}}$ during the supramaximal effort $(P=0.004)$. The RG presented higher peak and $\Delta[\mathrm{La}]$ than the $L T$, whereas the $\tau 1$ (i.e., time constant of the first exponential) in the RG was higher than in all the other groups. However, the $A_{1}$ $\left(\dot{\mathrm{VO}}_{2}\right.$ amplitude) in the RG was lower than in the ET (Table 3).

In addition, Figure 1 shows the oxygen equivalents from the $E_{[L a]}$ (Figure $\left.1(a, b)\right), E_{P C r}$ (Figure $1(c, d)$, and the MAOD ${ }_{A L T}$ values (Figure $1(\mathrm{e}, \mathrm{f})$ for all groups. For the values presented relative to body mass (i.e., $\mathrm{mL} \cdot \mathrm{kg}^{-1}$ ), the $\mathrm{RG}$ showed higher $\mathrm{E}$ [La], $E_{P C r}$, and $M_{A O D}$ ALT than the LT $(34.5,45.5$, and $36.4 \%$, respectively), MT $(17.9 \%, 32.5 \%$, and $19.8 \%$, respectively) and ET $\left(16.5,40.6\right.$, and $13.5 \%$, respectively), except for $E_{\text {[La] }}$ where the RG was statistically higher only in relation to the LT. For the absolute values (i.e., L) the outcomes were similar.

The magnitude-based inference analysis showed meaningful differences for $M A O D_{A L T}$ (both expressed in $L$ and $\mathrm{mL} \cdot \mathrm{kg}^{-1}$ ), presenting moderate to large ESs, and that $M_{A O D}$ ALT was effective in distinguishing individuals with different physical training backgrounds (Table 4) (Probability of difference: $\geq 92 \%$ between LT and MT; $\geq 99 \%$ between LT and ET; $100 \%$ between LT and RG; $\geq 98 \%$ between MT and RG; and $\geq 91 \%$ between ET and RG). Only the comparison between the MA and ET showed an unclear difference (ES $=-0.01 ; 31 \%$ of positive; $41 \%$ of trivial, and $28 \%$ of negative). The magnitudebased inference analysis also showed that $\mathrm{E}_{\mathrm{PCr}}$ and $\mathrm{E}_{[\mathrm{La}]}$ were effective for distinguishing individuals with different training status (Table 4); however, the magnitude-based inference analysis showed an unclear outcome for comparisons between LT and ET, and between MT and ET for both parameters.

\section{Discussion}

The purpose of the present study was to investigate the

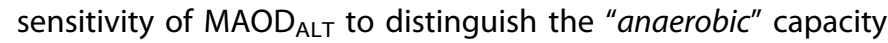
in groups with different levels of training. As hypothesised, MAOD $_{\mathrm{ALT}}$ was capable of discriminating between groups that are expected to display distinct levels of "anaerobic" capacities.
Team sports players are expected to present very high "anaerobic" pathway activity (Moore \& Murphy, 2003) to allow them to cope with match demands, which comprise high-intensity intermittent efforts and repeated sprints. For instance, one of the highest values of MAOD recorded in the literature was obtained in elite RG union players (99.4 $\mathrm{mL} \cdot \mathrm{kg}^{-1}$ ) (Moore \& Murphy, 2003). To our knowledge, there are no previous studies quantifying the MAOD in RG sevens players. However, their performance levels in sprint, repeated-sprint, Yo-Yo Intermittent Recovery Test level 1, and $\dot{\mathrm{V}}_{2 \max }$ can be considered high and comparable to other team sports players. For this reason, elite RG sevens players are expected to display superior $\mathrm{MAOD}_{\mathrm{ALT}}$ levels. In fact, our RG presented higher MAOD ALT $_{\text {than }}$ the ET (13.5\%), MT (19.8\%), and LT (36.4\%). These differences favouring the RG were reflected in both the $E_{P C r}$ and $E_{[L a]}$, demonstrating that $R G$ sevens players develop both the phosphagen and glycolytic pathways in their selection and training routines.

These findings were reinforced by magnitude-based inference analysis, with $\mathrm{MAOD}_{\mathrm{ALT}}$ presenting meaningful differences between LT vs. MT (likely meaningful), MT vs. RG (very likely meaningful) ET vs. RG (very likely meaningful), LT vs. ET (most likely meaningful), and LT vs. RG (most likely meaningful) (Table 4). The $E_{P C r}$ and $E_{[L a]}$ assessed in the RG were also higher than the other groups and presented very likely to most likely meaningful effects compared to the other groups. However, the unclear inference for comparisons between LT and ET, and between MT and ET could be attributed to infrequent high-intensity stimuli generally performed by these groups during exercise.

Concerning the sensitivity of MAOD to training effects, Heugas et al. (1997) reported that conventional MAOD was decreased after 3 months of intense aerobic training in elite sprint runners. In addition, Gastin and Lawson (1994) reported that ET cyclists presented similar conventional MAOD compared to untrained participants $\left(52\right.$ vs. $50 \mathrm{~mL} \cdot \mathrm{kg}^{-1}$, respectively), which were consistent with our findings [i.e., no significant difference $(P>0.05)$ ] among LT, MT, and ET individuals). However, as expected, both groups were inferior to sprint trained cyclists (when MAOD was expressed in absolute values) (Gastin \& Lawson, 1994). This is also consistent with our findings since RG players (the most "anaerobically" trained group) presented higher $M A O D_{A L T}$ that the other groups.

As aforementioned, the MAOD $\mathrm{ALT}_{\text {is }}$ is assessed from sums of the glycolytic and phosphagen metabolic pathways, which are estimated after a supramaximal effort until exhaustion (i.e. $115 \% \dot{\mathrm{VO}}_{2 \mathrm{EX}}$ ) which lasted between 102 and 218 s. According to Medbo et al. (1988), this effort is long enough for a severe depletion in intramuscular stores of phosphocreatine and 


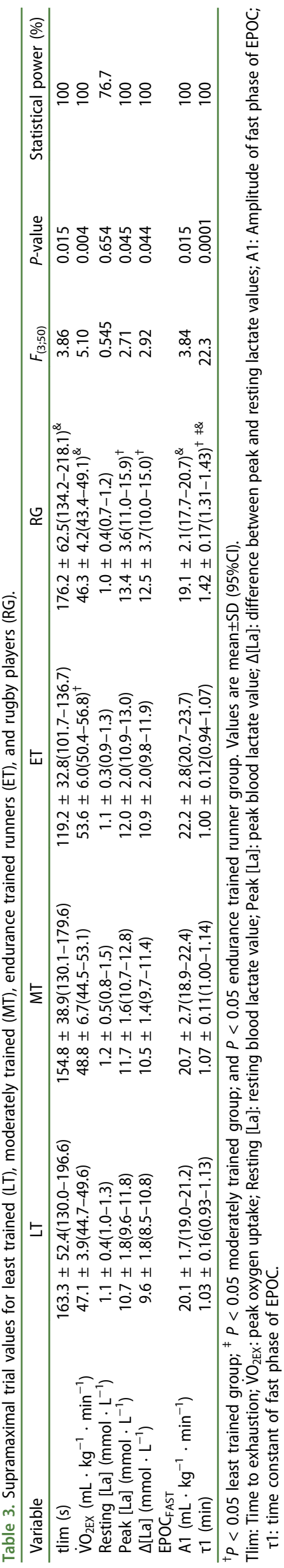

glycogen to occur. Therefore, the sum of oxygen equivalents from both non-mitochondrial pathways seems to correspond to the intramuscular "anaerobic" stores.

The assumptions accepted to estimate MAOD $_{\text {ALT }}$ have two important limitations. The first-one concerns the acceptance of the EPOC FAST to estimate the oxygen equivalent from the phosphagen pathway. Despite decades of the assumption that the initial seconds of EPOC are the oxygen above baseline values necessary to replenish the phosphocreatine $(\mathrm{PCr})$ depleted during high-intensity exercise, other studies have

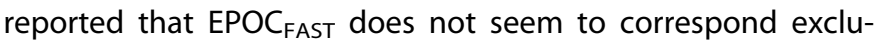
sively to replenishment of $\mathrm{PCr}$, also seeming to be influenced by the participation of the glycolytic pathway. However, Korzeniewski and Zoladz (2013) reported an inverse relationship between the $\mathrm{V}_{2}$ work-to-rest kinetics and the phosphocreatine work-to-rest kinetics in computer simulations, supporting the hypothesis that in fact the EPOC FAST $_{\text {corre- }}$ sponds to oxygen demand for the replenishment of PCr. It is relevant to point out that in our study the athletes with greater $\dot{\mathrm{V}}_{2 \max }$ values were the endurance athletes, whereas the RG were the group that had the greater magnitude of the phosphagen pathway (Table 4). Based on the fact that $\mathrm{VO}_{2}$ amplitude was not altered between the groups, it seems that a likely determinant factor for greater "anaerobic" capacity was a higher $\mathrm{\tau} 1$. The greater $\mathrm{\tau} 1$ found in the RG $(1.42 \pm 0.17 \mathrm{~min})$ indicates that these players take longer to replenish $\mathrm{PCr}$, probably due to the fact that these players have higher values of phosphocreatine (i.e., higher phosphagen pathway capacity).

The second limitation, and more relevant, is based on the fact that glycolytic pathway activity was estimated from blood lactate responses considering the difference between peak and resting values. In this procedure, we assumed the oxygen equivalent of $3.0 \mathrm{~mL} \cdot \mathrm{kg}^{-1}$ to each $1 \mathrm{mmol} \cdot \mathrm{L}^{-1}$ of $\Delta$ [La] (di Prampero \& Ferretti, 1999). Despite several studies having used this procedure to estimate the glycolytic metabolism pathway (Bertuzzi, Franchini, Kokubun, \& Kiss, 2007; Bertuzzi et al., 2010, 2015), this relationship was fitted using linear regression (di Prampero \& Ferretti, 1999) instead of a stoichiometric relationship. This means that this method is unable to establish a chemical equation that represents, at least in experimental conditions, the exact equivalence to its respective oxygen equivalent for each $1 \mathrm{mmol} \cdot \mathrm{L}^{-1}$ of blood lactate accumulated. Bangsbo et al. (1990) reported after a one-legged, dynamic knee-extensor exercise until exhaustion $(\approx 3.2 \mathrm{~min})$, that the muscle lactate concentration increased from 2 to $28.1 \mathrm{mmol} \cdot(\mathrm{kg} \text { wet } \mathrm{wt})^{-1}$, and the concomitant net lactate release was $14.8 \mathrm{mmol} \cdot(\mathrm{kg} \text { wet wt})^{-1}(1 / 3$ of the total net lactate production) and during recovery just $70 \%$ of the accumulated lactate was released to the blood. Additionally, the glycolytic metabolic pathway estimate from blood samples may not correspond exactly to the non-mitochondrial energy dispensed, however this measurement seems to be strongly related (di Prampero \& Ferretti, 1999; Margaria et al., 1933). In fact, this means that an athlete with higher blood lactate response in a maximal effort has greater muscular "anaerobic" capacity and/or power (Fujitsuka, Yamamoto, Ohkuwa, Saito, \& Miyamura, 1982). 


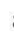
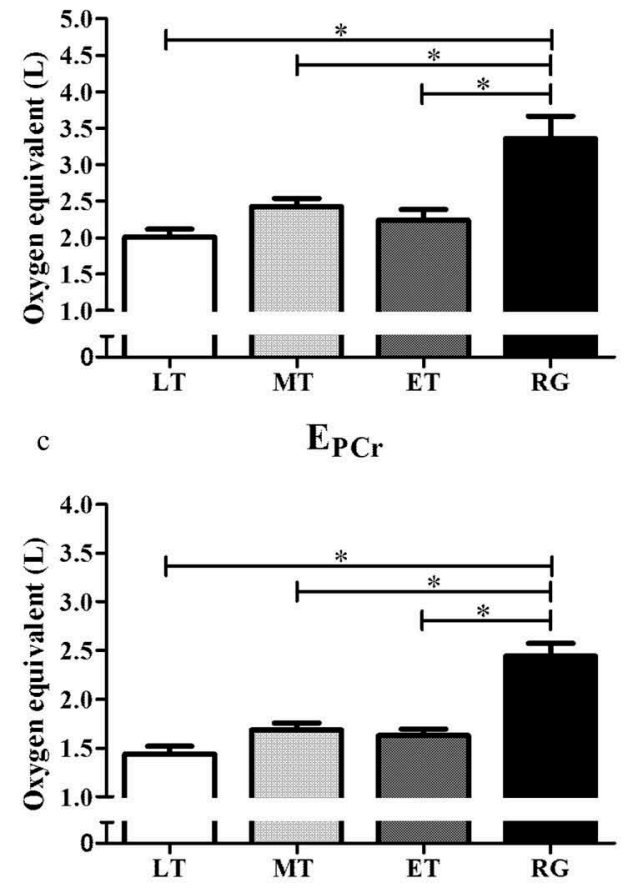

e

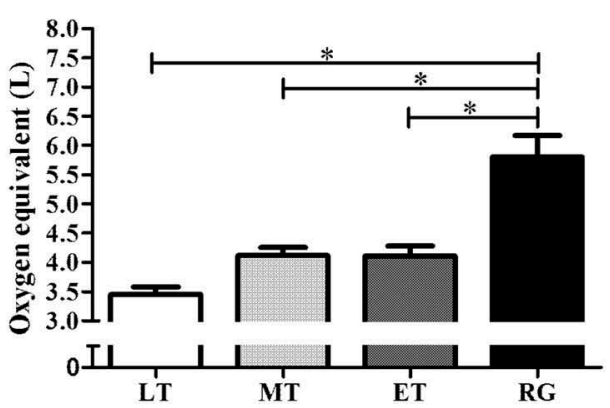

b $\quad \mathbf{E}_{[\text {La] }}$

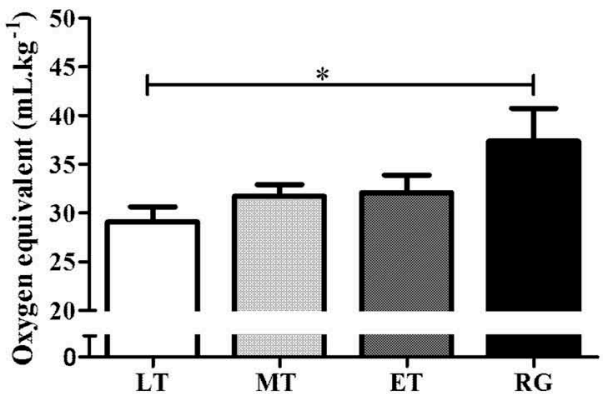

d

$\mathbf{E}_{\mathrm{PCr}}$

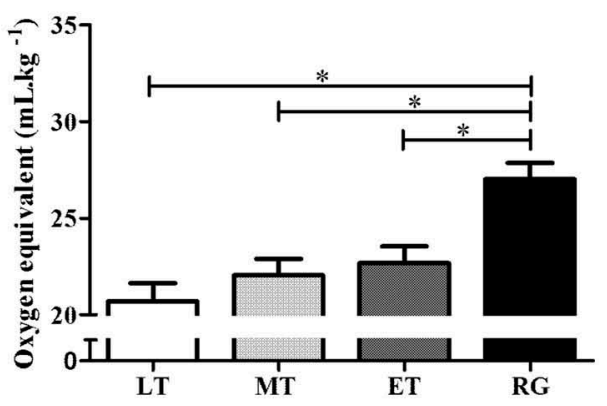

f $\quad$ MAOD ALT

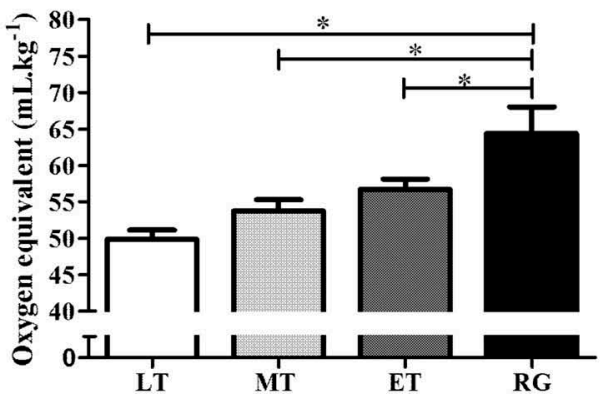

Figure 1. Means and standard deviation of oxygen equivalents from $E_{[L a]}$ (Figure $\left.1(a, b)\right)$ and $E_{P C r}$ (Figure $1(c, d)$ ), and the $M A O D_{A L T}$ values (Figure $1(e, f)$ for least trained (LT), moderately trained (MT),endurance trained runners (ET), and rugby sevens players (RG).Note: ${ }^{*} P<0.05$ as compared to RG.

Despite the aforementioned limitation concerning the contribution of the glycolytic pathway, it was reported that athletes with greater performance in short-distance events and with high non-mitochondrial activity (i.e., 100, 200, 400, and $800 \mathrm{~m}$ sprints) have higher blood lactate values after highintensity effort (Fujitsuka et al., 1982; Hautier et al., 1994; Lacour, Bouvat, \& Barthelemy, 1990). In this way, we understand that athletes with higher lactatemia are the athletes with greater glycolytic pathway capacity. This hypothesis is supported by significant differences found in blood lactate in the RG compared to the other groups (Table 4).

Despite our findings, until now, these findings do not allow the assumption that this procedure is able to determine the intramuscular "anaerobic" capacity; but we are reporting the sensitivity of $M A O D_{A L T}$ to different levels of training status. These findings suggest that the MAOD ${ }_{A L T}$ could be an attractive index to evaluate the "status of anaerobic conditioning" of athletes. It is important to note that the present study provides preliminary normative values of $M A O D_{A L T}$ to classify the "anaerobic" capacity of participants with different training backgrounds. Of note, previous studies have demonstrated values of $55.8 \mathrm{~mL} \cdot \mathrm{kg}^{-1}$ of $\mathrm{MAOD}_{\mathrm{ALT}}$ in recreationally trained runners (Milioni et al., 2016) and $\sim 52 \mathrm{~mL} \cdot \mathrm{kg}^{-1}$ of MAOD ALT in MT males (Brisola et al., 2015; Zagatto, Bertuzzi, et al., 2016), which are similar to the values presented herein $\left(53.8 \mathrm{~mL} \cdot \mathrm{kg}^{-1}\right.$ of $M A O D_{A L T}$ in the MT group). However, in the current study the different levels of training status were classified by training minutes per week instead of a physiological index such as $\dot{\mathrm{V}}_{2 \max }$, however training minutes per week was used because $\dot{\mathrm{VO}}_{2 \max }$ is not a good parameter to classify "anaerobic" fitness.

Therefore, we can conclude that MAOD ${ }_{A L T}$ assessed in treadmill running can be considered a sensitive enough procedure to distinguish the "anaerobic" capacity in individuals with different training levels. However, future studies should determine the MAOD ${ }_{A L T}$ values attained by sprint-trained athletes (e.g., 400-m dash), in order to define the values that can be attained at the extremes of human performance. Due to the single session needed to assess $M A O D_{A L T}$, it has high 
Table 4. Magnitude-based inference analysis of results from comparisons between groups.

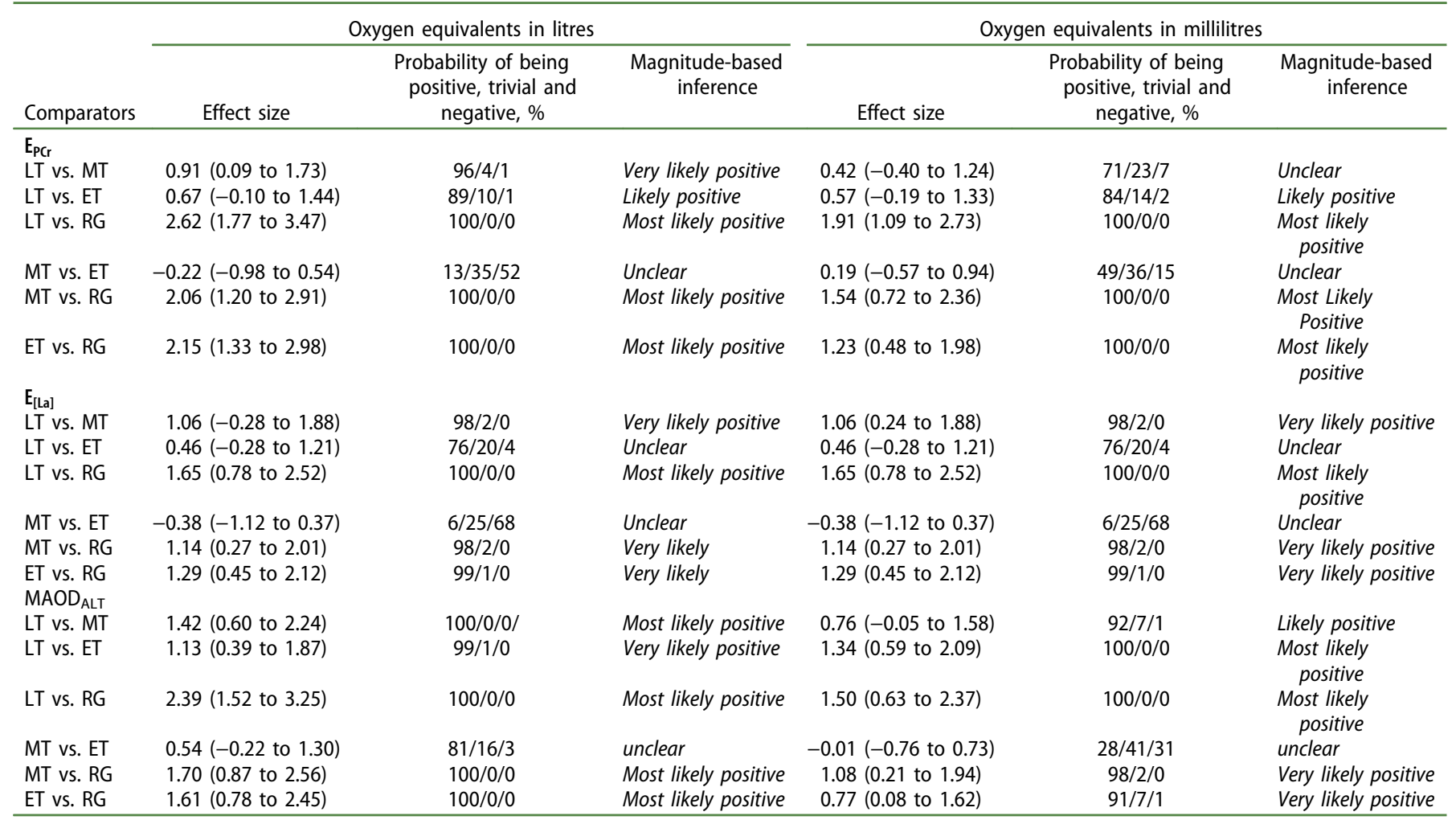

least trained (LT), moderately trained (MT), endurance trained runners (ET), and rugby players (RG).

$E_{\mathrm{PC}}$ : energy contribution (i.e., oxygen equivalents) from the phosphagen metabolic pathway; $\mathrm{E}_{[\mathrm{La}]}$ : energy contribution (i.e., oxygen equivalents) from the glycolysis metabolic pathway; $\mathrm{MAOD}_{\mathrm{ALT}}$ : Alternative maximal accumulated oxygen deficit method. The quantitative chances were assessed qualitatively as follow: $0.5-$ $5 \%=$ very unlikely; $5-25 \%=$ unlikely; $25-75 \%=$ possibly; $75-95 \%=$ likely; $95-99.5 \%=$ very likely; and $>99.5 \%=$ most likely

potential for practical application to assess "anaerobic" capacity. In addition, the MAOD ${ }_{A L T}$ can distinguish the energy contribution from the phosphagen and glycolytic pathways, an assessment which is not possible when using the conventional MAOD.

\section{Acknowledgement}

We are grateful to the Ireneu Loturco, director of the Nucleus of High Performance in Sport (NAR; São Paulo, Brazil), who made it possible to evaluate at Brazilian Rugby Sevens Team.

\section{Disclosure statement}

The authors declare no conflicts of interest.

\section{Funding}

This work was supported by grants from Fundação de Amparo à Pesquisa do Estado de São Paulo (FAPESP \#2013/12940-8). Miyagi WE was supported by FAPESP fellowship (FAPESP \#2014/02829-5).

\section{Ethical approval}

The author and co-authors have contributed substantially to this original work and approved the

final submission. This work is not being considered for publication, in whole or in part, in another

journal, book, or conference proceedings and the author and coauthors have no conflicts of interest.

The author and co-authors reviewed the final stages of the manuscript.
All procedures performed in studies involving human participants were in accordance with the ethical standards of the institutional and/or national research committee and with the 1964 Helsinki declaration and its later amendments or comparable ethical standards.

\section{ORCID}

Alessandro M. Zagatto (D) http://orcid.org/0000-0003-1065-4158 Johnny Padulo (ID) http://orcid.org/0000-0002-4254-3105 Nicola L. Bragazzi (D) http://orcid.org/0000-0001-8409-868X

\section{References}

Bangsbo, J., Gollnick, P. D., Graham, T. E., Juel, C., Kiens, B., Mizuno, M., \& Saltin, B. (1990). Anaerobic energy production and O2 deficit-debt relationship during exhaustive exercise in humans. The Journal of Physiology, 422, 539-559. doi:10.1113/jphysiol.1990.sp018000

Batterham, A. M., \& Cox, A. J. (2006). Spreadsheets for analysis of controlled trials, with adjustment for a subject characteristic. Sportscience, 10, 46-51.

Batterham, A. M., \& Hopkins, W. G. (2006). Making meaningful inferences about magnitudes. International Journal of Sports Physiology and Performance, 1(1), 50-57. doi:10.1123/ijspp.1.1.50

Bertuzzi, R., Kiss, M. A., Damasceno, M., Oliveira, R. S., \& Lima-Silva, A. E. (2015). Association between anaerobic components of the maximal accumulated oxygen deficit and 30-second Wingate test. Brazilian Journal of Medical and Biological Research, 48(3), 261-266. doi:10.1590/1414-431X20144043

Bertuzzi, R. C., Franchini, E., Kokubun, E., \& Kiss, M. A. (2007). Energy system contributions in indoor rock climbing. European Journal of Applied Physiology, 101(3), 293-300. doi:10.1007/s00421-007-0501-0

Bertuzzi, R. C. M., Franchini, E., Ugrinowitsch, C., Kokubun, E., Lima-Silva, A. E., Pires, F. O., ... Kiss, M. (2010). Predicting MAOD using only a 
supramaximal exhaustive test. International Journal of Sports Medicine, 31(7), 477-481. doi:10.1055/s-0030-1253375

Billat, V. L., Blondel, N., \& Berthoin, S. (1999). Determination of the velocity associated with the longest time to exhaustion at maximal oxygen uptake. European Journal of Applied Physiology and Occupational Physiology, 80(2), 159-161. doi:10.1007/s004210050573

Brisola, G. P., Miyagi, W. E., da Silva, H., \& Zagatto, A. M. (2015). Sodium bicarbonate supplementation improved MAOD but is not correlated with 200 and $400 \mathrm{~m}$ running performances: A double blind, crossover and placebo controlled study. Applied Physiology, Nutrition and Metabolism, 40(9), 931-937. doi:10.1139/apnm-2015-0036

Cohen, J. (1988). Statistical power analysis for the behavioral sciences. Hillsdale, NJ: L. Erlbaum Associates.

de Poli, R., Miyagi, W. E., Nakamura, F. Y., \& Zagatto, A. M. (2016). Caffeine improved time to exhaustion, but did not change alternative maximal accumulated oxygen deficit estimated during a single supramaximal running bout. International Journal of Sport Nutrition and Exercise Metabolism. Advance online publication. doi:10.1123/ijsnem.2016-0038

di Prampero, P. E. (1981). Energetics of muscular exercise. Reviews of Physiology, Biochemistry and Pharmacology, 89, 143-222.

di Prampero, P. E., \& Ferretti, G. (1999). The energetics of anaerobic muscle metabolism: A reappraisal of older and recent concepts. Respiration Physiology, 118(2-3), 103-115. doi:10.1016/S0034-5687(99)00083-3

Fujitsuka, N., Yamamoto, T., Ohkuwa, T., Saito, M., \& Miyamura, M. (1982). Peak blood lactate after short periods of maximal treadmill running European Journal of Applied Physiology and Occupational Physiology, 48 (3), 289-296. doi:10.1007/BF00430218

Gastin, P. B., \& Lawson, D. L. (1994). Influence of training status on maximal accumulated oxygen deficit during all-out cycle exercise. European Journal of Applied Physiology and Occupational Physiology, 69(4), 321330. doi:10.1007/BF00392038

Hautier, C. A., Wouassi, D., Arsac, L. M., Bitanga, E., Thiriet, P., \& Lacour, J. R. (1994). Relationships between postcompetition blood lactate concentration and average running velocity over $100-\mathrm{m}$ and $200-\mathrm{m}$ races. European Journal of Applied Physiology and Occupational Physiology, 68(6), 508-513. doi:10.1007/BF00599521

Heugas, A. M., Brisswalter, J., \& Vallier, J. M. (1997). Effect of a three month training period on the maximal oxygen deficiency in high level performance sprinters. Canadian Journal of Applied Physiology, 22(2), 171-181.

Hopkins, W. G., Marshall, S. W., Batterham, A. M., \& Hanin, J. (2009). Progressive statistics for studies in sports medicine and exercise science. Medicine and Science in Sports and Exercise, 41(1), 3-13. doi:10.1249/MSS.0b013e31818cb278

Korzeniewski, B., \& Zoladz, J. A. (2013). Slow VO2 off-kinetics in skeletal muscle is associated with fast $\mathrm{PCr}$ off-kinetics-and inversely. Journal of Applied Physiology, 115(5), 605-612. doi:10.1152/ japplphysiol.00469.2013
Kuipers, H., Verstappen, F. T., Keizer, H. A., Geurten, P., \& van, K. G. (1985). Variability of aerobic performance in the laboratory and its physiologic correlates. International Journal of Sports Medicine, 6(4), 197-201. doi:10.1055/s-2008-1025839

Lacour, J. R., Bouvat, E., \& Barthelemy, J. C. (1990). Post-competition blood lactate concentrations as indicators of anaerobic energy expenditure during 400-m and 800-m races. European Journal of Applied Physiology and Occupational Physiology, 61(3-4), 172-176. doi:10.1007/BF00357594

Margaria, R., Edwards, H. T., \& Dill, D. B. (1933). The possible mechanisms of contracting and paying the oxygen debt and the role of lactic acid in muscular contraction. The American Journal of Physiology, 106(3), 689-715.

Medbo, J. I., Mohn, A. C., Tabata, I., Bahr, R., Vaage, O., \& Sejersted, O. M. (1988). Anaerobic capacity determined by maximal accumulated $\mathrm{O} 2$ deficit. Journal of Applied Physiology, 64(1), 50-60.

Milioni, F., Malta, E. S., Rocha, L. G. S. A., Mesquita, C. A. A., Freitas, E. C., \& Zagatto, A. M. (2016). Acute administration of high doses of taurine does not substantially improve high-intensity running performance and the effect on maximal accumulated oxygen deficit is unclear. Applied Physiology, Nutrition and Metabolism, 41(5), 498-503. doi:10.1139/apnm-2015-0435

Moore, A., \& Murphy, A. (2003). Development of an anaerobic capacity test for field sport athletes. Journal of Science and Medicine in Sport, 6(3), 275-284. doi:10.1016/S1440-2440(03)80021-X

Noordhof, D. A., de Koning, J. J., \& Foster, C. (2010). The maximal accumulated oxygen deficit method: A valid and reliable measure of anaerobic capacity? Sports Medicine, 40(4), 285-302. doi:10.2165/11530390000000000-00000

Tanaka, H., Monahan, K. D., \& Seals, D. R. (2001). Age-predicted maximal heart rate revisited. Journal of the American College of Cardiology, 37(1), 153-156. doi:10.1016/S0735-1097(00)01054-8

Zagatto, A., Miranda, M. F., \& Gobatto, C. A. (2011). Critical power concept adapted for the specific table tennis test: Comparisons between exhaustion criteria, mathematical modeling, and correlation with gas exchange parameters. International Journal of Sports Medicine, 32(7), 503-510. doi:10.1055/s-0030-1270470

Zagatto, A. M., Leite, J.V., Papoti, M., \& Beneke, R. (2016). Energetics of table tennis and table tennis specific exercise testing. International Journal of Sports Physiology and Performance, 11(8), 1012-1017. doi:10.1123/ijspp.2015-0746

Zagatto, A. M., Bertuzzi, R., Miyagi, W. E., Padulo, J., \& Papoti, M. (2016). MAOD determined in a single supramaximal test: A study on the reliability and effects of supramaximal intensities. International Journal of Sports Medicine, 37(09), 700-707. doi:10.1055/s-0042-104413

Zagatto, A. M., \& Gobatto, C. A. (2012). Relationship between anaerobic parameters provided from MAOD and critical power model in specific table tennis test. International Journal of Sports Medicine, 33(8), 613620. doi:10.1055/s-0032-1304648 